\title{
Educational Intervention Impacts on Knowledge and Performance of Self-Care Practices among Type 2 Diabetes Mellitus Patients in Selected Hospitals in Southwestern, Nigeria
}

\author{
Oluwaseun Oluwafunmilayo Abiodun ${ }^{1 *}$, Adenike Ayobola E Olaogun ${ }^{2}$ and Adewale Oladayo \\ Akinpelu ${ }^{1}$ \\ ${ }^{1}$ Department of Nursing, Achievers University, Nigeria \\ ${ }^{2}$ Department of Nursing Science, Obafemi Awolowo University, Nigeria
}

*Corresponding author: Dr. Oluwaseun O Abiodun, Department of Nursing, Achievers University, Owo, Ondo State, Nigeria, Tel: 2348034236909

\section{Abstract}

Background: Neglecting the importance of adequate knowledge and correct performance of self-care practices are major causes of many complications that are experienced by T2DM patients. The objective of this study was to assess the impact of educational intervention on the level of knowledge and performance of self-care practices among patients with T2DM in selected tertiary hospitals.

Materials and Methods: A quasi-experimental design that utilized purposive sampling method was used. The study was conducted at the University of Medical Sciences Teaching Hospital, (UNIMEDTH) Akure, Ondo-State and Ekiti-State University Teaching Hospital (EKSUTH), Ado-Ekiti. Participants in UNIMEDTH (58) and EKSUTH (31) formed the experimental and control groups respectively. A structured questionnaire, an educational package and a focus group guide were used. Performance of SCP was evaluated with checking of recorded blood glucose, recall, demonstration and inspection.

Results: Results show that at the pre-intervention and six months post-intervention phases, $39.7 \%$ and $98.3 \%$ of the experimental group had good knowledge of SCP respectively. Similarly, $39.2 \%$ and $91.4 \%$ had good performance of SCP at the pre-intervention and six months post-intervention phases respectively. Lastly, the glycated hemoglobin (HBA1c) levels of participants in the experimental group improved significantly $<0.0001$ with the intervention.

Conclusion: Adequate education and training on SCP of T2DM patients improved the level of knowledge and performance of SCP with satisfactory improvements in the levels of HBA1C of participants in the experimental group.
\end{abstract}

\section{Keywords}

Knowledge, Performance, Self-care Practices, Type 2 Diabetes Mellitus

\begin{abstract}
Abbreviations
DM: Diabetes Mellitus; DSME: Diabetes Self-Management Education; IDF: International Diabetes Federation; HBA1c: Glycated Hemoglobin; EKSUTH - Ekiti-State University Teaching Hospital; UNIMEDTH: Ondo-State and Ekiti-State University Teaching Hospital; SCP: Self-Care Practices; T2DM: Type 2 Diabetes Mellitus; WHO: World Health Organization
\end{abstract}

\section{Introduction}

Diabetes mellitus (DM) is a major chronic public health concern due to its rapidly growing and enormous burden with serious though preventable consequences worldwide [1-3]. Globally, in 2015, the International Diabetes Federation [4] and World Health Organization [5] estimated that one out of eleven adults had diabetes while more than 40,800 deaths occurred from the disease. The IDF [6] also submitted that 451 million people ranging from age 18 to 99 years had DM in 2017 and approximately 5 million deaths were caused by the disease within the same age bracket in the year. The World Health Organization [7] reported that all over the world today, 485 million people are living with DM, out of this large number, 22 million and 4 million people

Citation: Abiodun OO, Olaogun AAE, Oladayo Akinpelu AO (2020) Educational Intervention Impacts on Knowledge and Performance of Self-Care Practices among Type 2 Diabetes Mellitus Patients in Selected Hospitals in Southwestern, Nigeria. Int J Diabetes Clin Res 7:124. doi.org/10.23937/23773634/1410124

Accepted: June 04, 2020: Published: June 06, 2020

Copyright: (C) 2020 Abiodun OO, et al. This is an open-access article distributed under the terms of the Creative Commons Attribution License, which permits unrestricted use, distribution, and reproduction in any medium, provided the original author and source are credited. 
are living in sub-Saharan Africa and Nigeria respectively.

However, in order to achieve normal blood glucose level which is needed to forestall the numerous complications and deaths from the disease, it is necessary for a person who has DM to make a lot of daily self-care decisions and engage in complex self-care activities $[8,9]$. These are otherwise known as self-care practices, they are; self-monitoring of blood glucose (SMBG), exercise, healthy eating, use of medications as prescribed, general body and foot care among others [10]. Self-care practices are activities engaged in on a daily basis with the aim of preventing the negative effects or complications of a disease that is affecting an individual [10]. At a broad level, it was defined as daily management of serious health conditions by individuals through adequate knowledge, abilities and skills' facilitation in diabetes self-care $[8,11]$. It further demands acquiring knowledge and necessary skills to be involved in the complex set of behaviours that are useful in health maintenance as individuals with a chronic disease in the context of day-to-day survival [10]. Diabetes self-care practices are considered key and very important in glyceamic control and individuals concerned use their resources, including personal attributes such as courage, skills, knowledge, determination, positive attitudes, will-power as well as optimism to make their health better [11-13].

Prevention of major and minor complications is one of the most valued goals in the management of type 2 diabetes mellitus (T2DM) [14]. Positive health outcomes of T2DM are tied to the level of patients' knowledge of the disease through health education and self-management using the health resources of the nations' [15]. According to [16], a well-informed patient will have the best advantage to attain and maintain glycaemic and cardiovascular risk factors control. Consequently, poor knowledge of self-care can cause poor long-term metabolic disorder which may lead to the development of diabetic complications such as retinopathy, nephropathy, neuropathy and atherosclerotic changes [17].

Studies have shown that increased patients' knowledge regarding the disease and its complications have significant benefits with regard to patients' compliance to treatment and to decreased complications associated with the disease $[18,19]$. This is directly linked to positive and desirable health outcomes [14]. Self-care practices have been generally accepted as key to achieving better glyceamic control in T2DM care [20]. Optimal and good health outcomes of patients with T2DM are linked to the levels of patients' knowledge on the disease and its management which are acquired through self-management education, adequate attention and commitment to self-care practices using available health resources $[14,15]$.

Diabetes self-management education (DSME) is the process of facilitating the skills, knowledge and ability needed for self-care of diabetes mellitus patients; it translates to the support which is required for initiating, maintaining and reinforcing essential coping skills as well as behaviours that are required for self-management on daily basis [8]. Educational intervention studies have been done in different parts of the world and have been adjudged as very effective in improving the level of knowledge of diabetes mellitus patients $[8,21]$. Educational programs must provide correct messages, reinforce and reiterate information that have been given earlier, ensure feedback regarding definitive self-care practices as well as problem-solving strategies to handle self-care problems to help patients discuss their self-care issues [22]. Knowledge has been described as the greatest weapon in fighting DM [23]. Acquiring enough knowledge enhances achievement and sustenance of acceptable glycaemic levels at all times $[13,16]$. Whereas, inadequate knowledge about self-care practices can result in long-term complications such as nephropathy, atherosclerosis, neuropathy, retinopathy and heart diseases $[24,25]$. Studies have established that increase in patients' knowledge about the disease and its complications have tremendous benefits with regard to patients' compliance to treatment and reduction of associated complications [23].

The role of adequate knowledge about diabetes mellitus and its self-care practices cannot be overemphasized as it goes a long way in assisting even in early detection of the disease and reduce its complications among those who already have the disease [23]. Empirical findings from numerous studies conducted in different parts of the world show that there is dearth in the level of knowledge about the disease process and management among many patients with diabetes $[26,27]$. Educational interventions in diabetes care have been proven to be cost-effective as they reduce hospital admissions, re-admissions, enhance improvement in self-efficacy, empowerment, HbA1c, quality of life and healthy coping [21].

\section{Objective}

The objective of the study was to assess the impact of educational intervention on the level of knowledge and performance of self-care practices as well as glycated haemoglobin (HBA1C) among patients with T2DM in selected tertiary hospitals in southwestern Nigeria.

\section{Materials and Methods}

\section{Study subjects and research design}

A quasi-experimental design that utilized purposive sampling method was used. This design lacks random assignment by identifying a comparison group with similar characteristics as the treatment group during the pre-intervention phase [28]. This design was chosen because two separate groups were involved and the research protocol was useful in allocating participan- 
ts to groups. Purposive sampling method was utilized because those that did not meet the inclusion criteria out of the study population were screened out and the selected sample shared common characteristics. The experimental group received the intervention of interest while the control group got no intervention [29].

The study was conducted at University of Medical Sciences Teaching Hospital, Akure (UNIMEDTH), Ondo-State and Ekiti-State University Teaching Hospital (EKSUTH), Ado-Ekiti. Ethical clearances were obtained from the Ethics and Research Committees of both hospitals. The inclusion criteria were; Patients that have been diagnosed of T2DM who were 18 years and above (both with fair and poor T2DM control), T2DM patients without diabetes complications like blindness, renal failure, and attending out-patient diabetes clinic in the study settings. The last one is that participants must not have attended any formal diabetes educational training in the last one year. The exclusion criteria were having serious mental challenges and being diagnosed less than three months before the commencement of the study. The participants in UNIMEDTHA formed the experimental group with 58 participants while those in EKSUTH formed the control group with 31 participants.

The total number of T2DM patients who attended the endocrine clinic of UNIMEDTHA between January and December 2018 was 2,833. This was the eligible population, this number was divided by 12 and it gave an average of 236 per month. Also, the total number of T2DM who were eligible at EKSUTH was 1,608, this number was divided by 12 and it gave an average of 134 per month. The number of participants in each group was calculated based on these. Initially, 82 and 48 participants were screened for the experimental and control groups respectively while 58 and 31 participants who met the inclusion criteria and consented to participate in the study after explaining all it entailed to them in both groups respectively were recruited.

\section{Data Collection}

A structured questionnaire was used to assess the level of knowledge at the pre-intervention phase, three and six months post-intervention respectively. The questionnaire had three sections, namely; Section A had 10 items that were used to collect socio-demographic data. Section B contained 10 items on knowledge of self-care practices. Section $C$ contained 20 items on performance of SCP from the "Modified Diabetes Self-care Questionnaire" (Revised) [30] and Self-care inventory; they were modified to integrate cultural differences after the pilot study. The pilot study took place in two tertiary hospitals in southwestern region of Nigeria too. This was done to know the workability of the instruments and make necessary adjustments. Participants were recruited using the inclusion criteria checklist. A total of 35 T2DM patients were recruited, 21 and 14 formed the experimental and control groups respectively. Details of the study were explained to participants first, those that asked questions were given appropriate answers. Blood tests for measurement of HBA1c were done first, then questionnaires were distributed and retrieved; same procedures were repeated for the control group at six and twelve weeks respectively. The experimental group was educated with the educational package during the second week. The focus group discussion was done with a group of ten in each group. Cronbach Alpha of the questionnaire after the pilot study was 0.815 .

This study took place from December, 2018 to May, 2019. Participants were recruited using the inclusion criteria checklist. A total of 89 T2DM patients were recruited, 58 and 31 formed the experimental and control groups respectively. Every detail of the study was explained to participants first, those that asked questions were given appropriate answers afterwards. Blood tests for measurement of HBA1c were done first, and then questionnaires were distributed and retrieved. Educational intervention was given to the experimental group and focus group discussion came last. The same procedures were repeated for the control group at three and six months respectively except the educational intervention.

The glycated haemoglobin (HBA1c) levels of participants in both groups were measured at the pre-intervention phase, at three months and six months post-intervention phases and they were recorded by the researchers. This was done with Kiptrack electronic table top analyzer which was made by Rapidcheck Diagnostics and Wellness Limited. The glycated haemoglobin test (HBA1c) was done by the researchers for each of the participant according to the machine's manual. Results were recorded against the code that was given to each of them.

Scoring of the items in section B of the questionnaire was done by allocating 1 for each correct and 0 for each incorrect answer respectively. The items were summed up to derive a composite score with higher scores reflecting increased knowledge of SCP while lower scores connote reduced SCP. Scores from 5-10 were considered as good while scores below 5 were regarded as poor. Therefore, scores from 5 to 10 connote good level of knowledge while those below 5 connote poor level of knowledge.

The educational package on SCP was used to train participants in the experimental group for one month on the SCP after the pre-intervention phase. It was adapted from the self-management module for educators of Kenya's National diabetes educators manual [31], same has been validated earlier [31]. It was modified by the researchers with literature searches and inputs from specialists in education and diabetes care. Face and content validity were established by experts in education and diabetes care also before it was used to teach participants in the experimental group over a 
Table 1: Socio-demographic characteristics of the participants.

\begin{tabular}{|c|c|c|c|c|c|c|}
\hline \multirow[t]{2}{*}{ Characteristics } & \multicolumn{2}{|l|}{ Control } & \multicolumn{2}{|c|}{ Experimental } & \multicolumn{2}{|l|}{ Total } \\
\hline & Frequency & $\%$ & Frequency & $\%$ & Frequency & $\%$ \\
\hline \multicolumn{7}{|l|}{ Gender } \\
\hline Male & 8 & $25.8 \%$ & 19 & $32.8 \%$ & 27 & $30.3 \%$ \\
\hline Female & 23 & $74.2 \%$ & 39 & $67.2 \%$ & 62 & $69.7 \%$ \\
\hline \multicolumn{7}{|l|}{ Age } \\
\hline Mean \pm SD & $60 \pm 11$ & & $63 \pm 12$ & & $62 \pm 12$ & \\
\hline$\leq 44$ years & 3 & $9.7 \%$ & 2 & $3.5 \%$ & 5 & $5.6 \%$ \\
\hline $45-54$ years & 7 & $22.6 \%$ & 10 & $17.2 \%$ & 17 & $19.1 \%$ \\
\hline $55-64$ years & 9 & $29.0 \%$ & 17 & $29.3 \%$ & 26 & $29.2 \%$ \\
\hline 65 years + & 12 & $38.7 \%$ & 29 & $50.0 \%$ & 41 & $46.1 \%$ \\
\hline \multicolumn{7}{|l|}{ Marital Status } \\
\hline Single & 2 & $6.5 \%$ & 2 & $3.5 \%$ & 4 & $4.5 \%$ \\
\hline Married & 21 & $67.7 \%$ & 35 & $60.3 \%$ & 56 & $62.9 \%$ \\
\hline Divorced/Widowed/Separated & 8 & $25.8 \%$ & 21 & $36.2 \%$ & 29 & $32.6 \%$ \\
\hline \multicolumn{7}{|l|}{ Education } \\
\hline No formal education & 2 & $6.5 \%$ & 2 & $3.5 \%$ & 4 & $4.5 \%$ \\
\hline Primary & 9 & $29.0 \%$ & 17 & $29.3 \%$ & 26 & $29.2 \%$ \\
\hline Secondary & 6 & $19.4 \%$ & 22 & $37.9 \%$ & 28 & $31.5 \%$ \\
\hline Diploma & 3 & $9.7 \%$ & 5 & $8.6 \%$ & 8 & $9.0 \%$ \\
\hline Bachelor's degree & 8 & $25.8 \%$ & 10 & $17.2 \%$ & 18 & $20.2 \%$ \\
\hline Post-graduate degree & 3 & $9.7 \%$ & 2 & $3.5 \%$ & 5 & $5.6 \%$ \\
\hline \multicolumn{7}{|l|}{ Tribe } \\
\hline Yoruba & 29 & $93.5 \%$ & 54 & $93.1 \%$ & 83 & $93.3 \%$ \\
\hline Others & 2 & $6.5 \%$ & 4 & $6.9 \%$ & 6 & $6.7 \%$ \\
\hline \multicolumn{7}{|l|}{ Employment Status } \\
\hline Unemployed & 10 & $32.3 \%$ & 11 & $19.0 \%$ & 21 & $23.6 \%$ \\
\hline Employed & 13 & $41.9 \%$ & 29 & $50.0 \%$ & 42 & $47.2 \%$ \\
\hline Retired & 8 & $25.8 \%$ & 18 & $31.0 \%$ & 26 & $29.2 \%$ \\
\hline \multicolumn{7}{|l|}{ Income } \\
\hline $5,000-10,000$ & 7 & $22.6 \%$ & 11 & $19.0 \%$ & 18 & $20.2 \%$ \\
\hline $11,000-50,000$ & 7 & $22.6 \%$ & 5 & $8.6 \%$ & 12 & $13.5 \%$ \\
\hline $51,000-100,000$ & 9 & $29.0 \%$ & 22 & $37.9 \%$ & 31 & $34.8 \%$ \\
\hline Above 100,000 & 8 & $25.8 \%$ & 20 & $34.5 \%$ & 28 & $31.5 \%$ \\
\hline Total & 31 & $100 \%$ & 58 & $100 \%$ & 89 & $100 \%$ \\
\hline
\end{tabular}

period by the researchers. Performance of SCP by participants in both groups was monitored and evaluated through checking of recorded blood glucose values that participants did and recorded at home, diet recall, where drugs were bought from, dosage and time of taking them, demonstration of leg inspection/care and inspection of legs and body during interactions.

Focus group discussion was done with two groups (each group had 10 participants) in the experimental and control groups each. The questions were designed by the researchers with the aid of literature search and were further modified with the result of the pilot study and inputs from experts in education and diabetes care. The researchers moderated each session with the aid of the guide. Notes were taken and each session was au- dio-recorded. Each group was engaged for an average of 78 minutes. Recorded data were transcribed verbatim later.

\section{Self-Care Practices Performance were Valida- ted as Follows}

Self-Monitoring of Blood Glucose - All participant were given exercise books in which they recorded their blood glucose values with dates. The contents of the exercise books were checked each time we met for interaction and values were recorded in the researchers' notebook.

Healthy eating - Diet recall was used.

Compliance with Medication - Where medications 
were procured, how they were being kept and how they were being taken were closely monitored through self-report.

Exercise - Participants were asked to demonstrate the exercises they were doing at home. Recall was also used to monitor this SCP.

General body and Foot care - Inspection of foot wears were done during meetings and interactions. Self-reporting and demonstration of foot inspection were also used.

\section{Data Analysis}

Frequencies and percentages were used to analyze the socio-demographic data and the levels of knowledge and performance of SCP. Chi-square test was used to test relationships between self-care practices and socio-demographic characteristics while binary logistics regression was adopted to explain relationships between the levels of knowledge and performance of self-care practices (SBGM, healthy eating, medication adheren- ce, exercise general body and foot care) and selected socio-demographic data. One-way analysis of variance (1-way ANOVA) was used to determine whether there was any statistically significant difference between the mean values of HBA1c of both groups. Thematic analysis was used for qualitative data. All calculations were done using Stata 14 (StataCorp, 2015).

\section{Results}

Table 1 shows descriptive analysis of the socio-demographic characteristics of all study participants. Female participants accounted for a higher proportion 23 (74.2\%) and 39 (67.2\%) in the control and experimental groups respectively. The distribution of participants' according to age revealed that a higher proportion of the participants were above 65 years of age, $12(38.7 \%)$ and $29(50.0 \%)$ in the control and experimental groups respectively. Ages of participants ranged from 22 to 75 years, the mean age for all participants was $62 \pm 12$. Other details are as shown on the table.

Table 2: Descriptive analysis of levels of knowledge and performance of self-care practices in both groups.

\begin{tabular}{|c|c|c|c|c|c|c|}
\hline \multirow[t]{2}{*}{ Groups } & \multicolumn{2}{|c|}{ Pre-intervention } & \multicolumn{2}{|c|}{3 months post-intervention } & \multicolumn{2}{|c|}{6 months post- intervention } \\
\hline & Frequency & $\%$ & Frequency & $\%$ & Frequency & $\%$ \\
\hline \multicolumn{7}{|l|}{ Control } \\
\hline \multicolumn{7}{|l|}{ Knowledge of SCP } \\
\hline Poor knowledge & 19 & $61.30 \%$ & 23 & $74.20 \%$ & 25 & $80.70 \%$ \\
\hline Good knowledge & 12 & $38.70 \%$ & 8 & $25.80 \%$ & 6 & $19.30 \%$ \\
\hline \multicolumn{7}{|c|}{ Performance of SCP } \\
\hline Poor performance & 24 & $77.40 \%$ & 22 & $71.00 \%$ & 20 & $64.50 \%$ \\
\hline Good performance & 7 & $22.60 \%$ & 9 & $29.00 \%$ & 11 & $35.50 \%$ \\
\hline \multicolumn{7}{|l|}{ Experimental } \\
\hline \multicolumn{7}{|l|}{ Knowledge of SCP } \\
\hline Poor knowledge & 35 & $60.30 \%$ & 16 & $27.60 \%$ & 1 & $1.70 \%$ \\
\hline Good knowledge & 23 & $39.70 \%$ & 42 & $72.40 \%$ & 57 & $98.30 \%$ \\
\hline \multicolumn{7}{|c|}{ Performance of SCP } \\
\hline Poor performance & 37 & $63.80 \%$ & 20 & $34.50 \%$ & 5 & $8.60 \%$ \\
\hline Good performance & 21 & $39.20 \%$ & 38 & $65.50 \%$ & 53 & $91.40 \%$ \\
\hline
\end{tabular}

Table 2 shows that at the pre-intervention phase, the control and experimental groups had poor knowledge of self-care practices. Specifically, $61.3 \%$ and $60.3 \%$ of the control and experimental groups reported poor knowledge of self-care practices. Similarly, performance of self-care practices between the control and experimental groups was also poor. Over three-quarter $(77.4 \%)$ of the control group and about two-third $(63.8 \%)$ of the experimental group reported poor performance of self-care practices.

In the same vein, performance of self-care practices of the control group remained poor (34.5\%) and that of the experimental group increased to (65.5\%). At six months post-intervention phase, both level of knowledge and performance of SCP were statistically significant (98.3\%) and (91.4\%) respectively, this was corroborated by reports of group FGD B of the experimental group after six months of educational intervention on SCP "I have known more since you began to teach us on how to take care of ourselves", "My health is better now", "I do not get tired easily as I used to because I now exercise every day and eat lesser than I used to". However, both levels of knowledge and performance of SCP in the control group remained poor. 
Table 3: Analysis of level of knowledge of self-care practices among participants by outcomes.

\begin{tabular}{|c|c|c|c|c|}
\hline \multirow{2}{*}{$\begin{array}{l}\text { Phases of intervention, Outcomes and } \\
\text { levels of measurements }\end{array}$} & \multicolumn{2}{|l|}{ Control } & \multicolumn{2}{|c|}{ Experimental } \\
\hline & Frequency & $\%$ & Frequency & $\%$ \\
\hline \multicolumn{5}{|l|}{ Pre-Intervention } \\
\hline \multicolumn{5}{|l|}{ SBGM } \\
\hline Poor & 25 & 80.6 & 46 & 79.3 \\
\hline Good & 6 & 19.4 & 12 & 20.7 \\
\hline \multicolumn{5}{|l|}{ Healthy Eating } \\
\hline Poor & 23 & 74.0 & 43 & 74.1 \\
\hline Good & 8 & 26.0 & 15 & 25.9 \\
\hline \multicolumn{5}{|l|}{ Medication Adherence } \\
\hline Poor & 12 & 38.7 & 21 & 36.2 \\
\hline Good & 19 & 61.3 & 37 & 63.8 \\
\hline \multicolumn{5}{|l|}{ General body and footcare } \\
\hline Poor & 18 & 58.1 & 25 & 43.1 \\
\hline Good & 13 & 41.9 & 33 & 56.9 \\
\hline \multicolumn{5}{|l|}{ Exercise } \\
\hline Poor & 14 & 45.2 & 32 & 55.2 \\
\hline Good & 17 & 54.8 & 26 & 44.8 \\
\hline \multicolumn{5}{|l|}{ Three Months } \\
\hline \multicolumn{5}{|l|}{ SBGM } \\
\hline Poor & 22 & 71.0 & 10 & 17.2 \\
\hline Good & 9 & 29.0 & 45 & 77.6 \\
\hline \multicolumn{5}{|l|}{ Healthy Eating } \\
\hline Poor & 19 & 61.3 & 15 & 25.9 \\
\hline Good & 12 & 38.7 & 43 & 74.1 \\
\hline \multicolumn{5}{|l|}{ Medication Adherence } \\
\hline Poor & 10 & 32.3 & 4 & 6.9 \\
\hline Good & 21 & 67.7 & 54 & 93.1 \\
\hline \multicolumn{5}{|l|}{ General body and foot care } \\
\hline Poor & 12 & 38.7 & 8 & 13.8 \\
\hline Good & 19 & 61.3 & 50 & 86.2 \\
\hline \multicolumn{5}{|l|}{ Exercise } \\
\hline Poor & 15 & 48.4 & 12 & 20.7 \\
\hline Good & 16 & 51.6 & 46 & 79.3 \\
\hline \multicolumn{5}{|l|}{ Six Months } \\
\hline \multicolumn{5}{|l|}{ SBGM } \\
\hline Poor & 17 & 54.8 & 4 & 6.9 \\
\hline Good & 14 & 45.2 & 54 & 93.1 \\
\hline \multicolumn{5}{|l|}{ Healthy Eating } \\
\hline Poor & 13 & 41.9 & 13 & 22.4 \\
\hline Good & 18 & 58.1 & 45 & 77.6 \\
\hline \multicolumn{5}{|l|}{ Medication Adherence } \\
\hline Poor & 9 & 29.0 & 1 & 1.7 \\
\hline Good & 22 & 71.0 & 57 & 98.3 \\
\hline \multicolumn{5}{|l|}{ General body and footcare } \\
\hline Poor & 21 & 67.7 & 6 & 10.3 \\
\hline Good & 10 & 32.3 & 52 & 89.7 \\
\hline \multicolumn{5}{|l|}{ Exercise } \\
\hline Poor & 11 & 35.5 & 10 & 17.2 \\
\hline Good & 20 & 64.5 & 48 & 83.6 \\
\hline
\end{tabular}


Table 3 presents the results of the assessment of the level of knowledge of self-care practices among study participants by outcome domains. There are five domains of self-care practices including SBGM, healthy eating, medication adherence, general body foot care and exercise. At pre-intervention stage, $19.4 \%$ and $20.7 \%$ of the control and experimental groups respectively reported good SBGM; $26.0 \%$ and $25.9 \%$ of the control and experimental groups respectively reported good healthy eating. Furthermore, $61.3 \%$ and $63.8 \%$ of the control and experimental groups reported good medication adherence, $41.9 \%$ and $56.9 \%$ of the control and experimental groups respectively reported good general body and foot care; $54.8 \%$ and $44.8 \%$ of the control and experimental groups respectively reported good exercise.
At six months, $45.2 \%$ and $93.1 \%$ reported good SBGM in the control and experimental groups respectively, $58.1 \%$ and $77.6 \%$ reported good healthy eating, $71.0 \%$ and $98.3 \%$ reported good medication adherence, $32.3 \%$ and $89.7 \%$ reported good general and body foot care while $64.5 \%$ and $83.6 \%$ reported good exercise. These findings were corroborated by reports of FGDB of the experimental group at three months post-intervention as follows; "Thank you our nurse, I am now fine because I don't eat as much as I used to do now", "I now exercise regularly", "I am doing well since I began to follow your advice, thank you nurse", "I eat healthy diet now as you taught us and I am much better now".

Table 4: Odds ratio of binary logistic regression showing influence of socio-demographic characteristics on self-care practices.

\begin{tabular}{|c|c|c|c|c|c|c|c|c|c|c|}
\hline \multirow[t]{2}{*}{$\begin{array}{l}\text { Characteristics } \\
\text { predicting SCP }\end{array}$} & \multicolumn{2}{|l|}{ SBGM } & \multicolumn{2}{|c|}{ Healthy Eating } & \multicolumn{2}{|c|}{$\begin{array}{l}\text { Medication } \\
\text { Adherence }\end{array}$} & \multicolumn{2}{|c|}{$\begin{array}{l}\text { General body and } \\
\text { foot care }\end{array}$} & \multicolumn{2}{|c|}{ Exercise } \\
\hline & OR & $p$-value & OR & $\mathrm{p}$-value & OR & $p$-value & OR & $p$-value & OR & $\mathrm{p}$-value \\
\hline \multicolumn{11}{|l|}{ Gender } \\
\hline Male ${ }^{R C}$ & 1.000 & - & 1.000 & - & 1.000 & - & 1.000 & - & 1.000 & - \\
\hline Female & 2.651 & 0.002 & 1.022 & 0.030 & 1.443 & 0.050 & 0.446 & 0.043 & 1.049 & 0.019 \\
\hline \multicolumn{11}{|l|}{ Age } \\
\hline$<44$ years $^{\mathrm{RC}}$ & 1.000 & - & 1.000 & - & & & 1.000 & - & 1.000 & - \\
\hline $45-54$ years & 1.231 & 0.030 & 1.445 & 0.006 & 1.317 & 0.046 & 1.435 & 0.019 & 1.000 & 0.071 \\
\hline $55-64$ years & 1.451 & 0.010 & 1.499 & 0.047 & 1.822 & 0.052 & 1.493 & 0.029 & 1.165 & 0.476 \\
\hline 65 years + & 2.110 & 0.001 & 0.672 & 0.764 & 1.816 & 0.008 & 1.541 & 0.151 & 1.227 & 0.096 \\
\hline \multicolumn{11}{|l|}{ Education } \\
\hline Primary ${ }^{R C}$ & 1.000 & - & 1.000 & - & 1.000 & - & 1.000 & - & 1.000 & - \\
\hline Secondary & 1.345 & 0.030 & 1.659 & 0.009 & 1.600 & 0.007 & 1.154 & 0.017 & 1.307 & 0.489 \\
\hline Higher & 1.567 & 0.003 & 1.925 & 0.026 & 1.639 & 0.006 & 1.642 & 0.007 & 1.719 & 0.251 \\
\hline \multicolumn{11}{|l|}{ Income } \\
\hline $5000-10,000^{R C}$ & 1.000 & - & 1.000 & - & 1.000 & - & 1.000 & - & 1.000 & - \\
\hline $11,000-50,000$ & 1.242 & 0.006 & 1.153 & 0.006 & 1.000 & 0.007 & 1.069 & 0.608 & 1.018 & 0.001 \\
\hline $51,000-100,000$ & 1.621 & 0.021 & 1.163 & 0.027 & 1.222 & 0.021 & 1.410 & 0.052 & 1.068 & 0.027 \\
\hline $100,001+$ & 1.717 & 0.006 & 1.720 & 0.178 & 1.673 & 0.047 & 1.926 & 0.016 & 1.712 & 0.436 \\
\hline
\end{tabular}

RC: Reference Category; OR: Odd Ratios

Table 4 presents the results of the binary logistic regression, it shows that females were twice more likely to have had good level of SBGM $(O R=2.651)$ and also more likely to have been better in medication adherence $(O R=1.022)$, healthy eating $(O R=1.443)$ and exercise $(O R=1.049)$ than males. It is also shown on the table that participants who were 65 years and above were twice more likely to have had good levels of SMBG (OR $=2.110$ ), while they were more likely to have had good levels of medication adherence $(O R=1.816)$, exercise $(O R=1.227)$ as well as general body and foot care (OR $=1.541)$.

In addition, socio-demographic factors such as gender, age, education and income of the participants had significant influence on SBGM, healthy eating, medication adherence, general body and foot care and exercise with $(p \leq 0.05)$. Other details are as shown on the table. 
Table 5: Analysis of glycated haemoglobin (HBA1c) for control and experimental groups.

\begin{tabular}{|c|c|c|c|c|c|c|c|}
\hline \multirow{2}{*}{\multicolumn{2}{|c|}{$\begin{array}{l}\text { Analysis of } \mathrm{HbA} 1 \mathrm{C} \text { values for Control } \\
\text { and Experimental Group Intervention }\end{array}$}} & \multirow{3}{*}{$\begin{array}{l}\mathbf{N} \\
31\end{array}$} & \multirow{3}{*}{$\begin{array}{l}\text { Mean } \pm \text { SD } \\
8.29 \pm 3.97\end{array}$} & \multirow{3}{*}{\begin{tabular}{|l|} 
Standard \\
Error \\
0.712 \\
\end{tabular}} & \multirow{3}{*}{$\begin{array}{l}\text { 95\% C.I. for mean } \\
\text { HbA1C } \\
\text { Lower - Upper } \\
6.839-9.747 \\
\end{array}$} & \multirow[b]{2}{*}{ F-ratio } & \multirow[b]{2}{*}{ p-value } \\
\hline & & & & & & & \\
\hline \multirow{3}{*}{ Control Group } & Pre-intervention & & & & & \multirow[b]{3}{*}{2.475} & \multirow[b]{3}{*}{0.09} \\
\hline & 3 months post- & 31 & $7.25 \pm 2.42$ & 0.435 & $6.359-8.137$ & & \\
\hline & 6 months post- & 31 & $6.64 \pm 2.13$ & 0.382 & $5.864-7.423$ & & \\
\hline \multirow{3}{*}{$\begin{array}{l}\text { Experimental } \\
\text { Group }\end{array}$} & Pre-intervention & 58 & $6.65 \pm 2.35$ & 0.308 & 6.031-7.265 & \multirow[b]{3}{*}{12.739} & \multirow[b]{3}{*}{$<0.0001$} \\
\hline & 3 months post- & 58 & $5.63 \pm 0.95$ & 0.125 & $5.376-5.876$ & & \\
\hline & 6 months post- & 58 & $5.21 \pm 1.03$ & 0.136 & $4.939-5.483$ & & \\
\hline
\end{tabular}

$\mathrm{N}$ is the Number of participants; Experimental group $=58$; Control group $=31$.

Table 5 shows the results of the assessment and measurement of participants' Haemoglobin A1C (HbA1C) at pre-intervention, 3 months post-intervention and 6 months post-intervention and the F-ratio and $p$-value of One-Way analysis of variance (1-way ANOVA) results at $5 \%$ level of significance in both experimental and control groups. The results shows that in the control group, the mean Haemoglobin A1C (HbA1C) is $8.29 \pm 3.97 \mathrm{mmol} / \mathrm{l}$ at pre-intervention, $7.25 \pm 2.42 \mathrm{mmol} / \mathrm{l}$ at 3 months post-intervention and $6.64 \pm 2.13 \mathrm{mmol} / \mathrm{l}$ at 6 months post-intervention. The lower and upper boundary of the $95 \%$ C.I. for Haemoglobin A1C (HbA1C) measured at pre-intervention was $6.839 \mathrm{mmol} / \mathrm{l}$ and $9.747 \mathrm{mmol} / \mathrm{l}$, respectively while the lower and upper boundary of the $95 \%$ C.I. for mean Haemoglobin A1C (HbA1C) measured at 6 months post-intervention was $5.864 \mathrm{mmol} / \mathrm{l}$ and $7.243 \mathrm{mmol} / \mathrm{l}$, respectively. The analysis of variance revealed that there is no significant difference in the measured $\mathrm{HbA} 1 \mathrm{C}$ between data collected at the pre-intervention and post-intervention in the control group (F-ratio $=2.475 ; p=0.090)$.

Furthermore, in the experimental group, the mean Haemoglobin $\mathrm{A} 1 \mathrm{C}(\mathrm{HbA1C})$ is $6.65 \pm 2.35 \mathrm{mmol} / \mathrm{l}$ at pre-intervention, $5.63 \pm 0.95 \mathrm{mmol} / \mathrm{l}$ at 3 months post-intervention and $5.21 \pm 1.03 \mathrm{mmol} / \mathrm{l}$ at 6 months post-intervention. The lower and upper boundary of the $95 \%$ C.I. for mean Haemoglobin A1C (HbA1C) measured at pre-intervention was $6.031 \mathrm{mmol} / \mathrm{l}$ and 7.265 $\mathrm{mmol} / \mathrm{l}$, respectively; lower and upper boundary of the 95\% C.I. Mean Haemoglobin A1C (HbA1C) measured at 6 months post-intervention was $4.939 \mathrm{mmol} / \mathrm{l}$ and 5.483 $\mathrm{mmol} / \mathrm{l}$, respectively. The analysis of variance revealed that there is significant difference in the measured $\mathrm{HbA1C}$ between data collected at the pre-intervention and post-intervention in the experimental group (F-ratio $=12.739 ; p<0.0001$ ). Other details are as shown in the table.

\section{Discussion}

Diabetes educational intervention has been proven to be helpful in the management of diabetes with several positive results as shown in the body of literature worldwide [21]. It helps to improve knowledge and performance of self-care practices which has been adju- dged as key to good glycaemic control for better outcomes [10]. Adequate knowledge on self-care practices and commitment to performance are very important in achieving and sustaining optimal blood glucose levels. Prevention of all forms of complications is a very important goal in the treatment of T2DM [24,25].

The two groups (experimental and control) that participated in the study had similar characteristics. There was female preponderance in both groups. This is consistent with many other findings on diabetes mellitus studies, some of them are; $[13,23,32,33]$. This may not be unrelated to factors bothering on positive attitude of women to treatment [34] and prevalence of obesity among women which is a major risk factor for the development of diabetes mellitus as opined by [35-37]. The result also revealed that a higher proportion of the participants were above 65 years of age and the mean age of the participants in the control and experimental groups were $60 \pm 11$ and $63 \pm 12$ respectively while that of all participants was $62 \pm 12$. This is consistent with the fact that T2DM is commoner among individuals who are 45 years and above because its risk increases with age as reported by many other studies on diabetes $[2,23,32,38-40]$.

The study also revealed that a higher proportion of the participants were married in both groups. This is consistent with the previous reports from $[23,41,42]$. This is not strange because of the ages of the participants. It was also revealed that almost all the participants had formal education in both groups although a higher proportion had primary and secondary education in both groups. This agrees with reports from previous studies by $[23,42]$. The differences may be attributed to the several socio-economic disparities that exists in the society and the fact that majority are above 60 years of age. However, those that were taught understood the content of the educational package. Many of the participants were of Christian faith and Yoruba in both groups while the remaining few belong to some other religions because the study locations are dominated by Christians and Yorubas.

Employment status of the participants as at the time of data collection showed that barely half of the partici- 
pants were employed in both groups. This is in contrast with the findings of $[42,43]$. The contrast may be due to the differences in settings and characteristics of participants. Participants who earned above N100,000.00 monthly were not many in both groups, this is consistent with the study of [42]. Variations in participants' income may be related to the asymmetrical nature of income because it is usually not normally distributed across various social classes. The participants who earned below $\mathrm{N} 100,000.00$ in both groups may not be finding it easy because of the high rate of inflation in Nigeria which is 11.08 currently [44].

It was shown that at pre-intervention stage, both the control and experimental groups had poor knowledge of self-care practices but at three and six months, the knowledge level of the experimental group increased and became statistically significant while that of the control group remained poor. However, this finding is corroborated by the reports on knowledge of self-care among T2DM patients in two states of Nigeria $[14,15,45,46]$.

It was clearly shown that analysis of the levels of knowledge by outcomes domain revealed that to a very large extent, participants in the experimental group had good knowledge of the five domains (self-blood glucose monitoring, healthy eating, medication adherence, general body foot care and exercise), this is in partial agreement with the findings of $[23,47]$. On the other hand, findings on the performance of self-care practices between the control and experimental groups were also poor at the pre-intervention phase. At three months and six months post-intervention phases, the levels of performance of SCP of the experimental group increased significantly while that of the control group remained poor. This is related to these findings $[23,46,47]$. Improvements in the level of SCP are related to the influence of the educational intervention that was given to the experimental group.

Also, the results of the binary logistic regression showed that female participants were twice more likely to have performed SBGM and more likely to have had better medication adherence and engaged in healthy eating and exercise than males. This is in contrast with the finding that showed that males had more knowledge of SCP [48]. Also, participants who were 65 years and above were more likely to have had good levels of medication adherence, general body and foot care as well as exercise. The contrast may be as a result of the comprehensive intervention that was given on SCP to the experimental group in this study. It was also revealed that a higher income and higher level of education were associated the SCP domains to a large extent, these findings are consistent with those of these authors $[32,48]$. However, the level of knowledge of the control group was consistently poor with variations in the levels of performance of SCP.
Furthermore, analysis of the glycated hemoglobin (HBA1c) of participants revealed that there was reduction in HBA1c of participants in the experimental group. This is related to the findings of some authors in their studies $[23,46]$. Improvements in the levels of knowledge and performance of SCP of participants in the experimental group are related to the influence of the educational intervention that was given to them. Therefore, educational intervention is very vital in improving T2DM patients' levels of knowledge and performance of glyceamic levels in other to avoid numerous complications that are associated with T2DM [32].

\section{Limitations}

The major limitation of the study was the sample size, although it was calculated based on the proportion of patients that attended the endocrine clinics of the two settings that were utilized for the study.

\section{Conclusion}

The study concluded that adequate education on SCP impacts the levels of knowledge and performance of self-care practices which are very important in achieving and sustaining optimal HBA1c and blood glucose levels among patients with T2DM positively. This was demonstrated in the experimental group at three and six months post-intervention with improvements in their HBA1c levels.

\section{Acknowledgements}

There is no conflict of interest at all. We thank all our research assistants and unit heads of the study settings. Also, we thank Ministry of Public Health and Sanitaition, Kenya for the Self-management National Diabetes Educators Manual that was adopted and Schmitt A, Gahr A, Hermanns N, Kulzer B, Huber J \& Haak T for the The Diabetes Self-Management Questionnaire (DSMQ).

\section{Sources of Support}

No funding was received from any organization.

\section{Statement of Equal Authors' Contribution}

All the authors contributed to the research work up to this level.

\section{References}

1. Herman WH (2017) Global burden of diabetes: An overview. In: Dagogo-Jack S, Diabetes mellitus in developing countries and underserved communities. Springer, Switzerland, 1-5.

2. Alotaibi A, Perry L, Gholizadeh L, Al-Ganmi A (2017) Incidence and prevalence rates of diabetes mellitus in Saudi Arabia: An overview. J Epidemiol Glob Health 7: 211-218.

3. World Health Organization (2018) Diabetes-statistics and facts.

4. International Diabetes Federation Africa (2015) Nigeria versus world prevalence of diabetes.

5. World Health Organization (2015) Media Centre Diabetes. Geneva, Switzerland. 
6. International Diabetes Federation (2018) Diabetes fact sheet.

7. World Population Review (2019) Nigeria population 2019.

8. Powers MA, Bardsley J, Cypress M, Duker P, Funnell MM, et al. (2015) Diabetes self-management education and support in type 2 diabetes: A joint position statement of the American Diabetes Association, the American Association of Diabetes Educators, and the Academy of Nutrition and Dietetics. Diabetes Care 38: 1372-1382.

9. Khardori $R$ (2016) Type 2 diabetes mellitus treatment \& management: American Diabetes Association Standards of medical care in diabetes. Diabetes Care 35: S11-S63.

10. Reyes J, Tripp-Reimer T, Parker E, Muller B, Laroche E (2017) Factors influencing diabetes self-management among medically underserved patients with type II diabetes. Glob Qual Nurs Res 4: 1-13.

11. Daoud N, Osman A, Hart TA, Berry EM, Adler B (2014) Self-care management among patients with type 2 diabetes in East Jerusalem. Health Education Journal 74: 603-615.

12. Akinsola $H$ (2001) Fostering hope in people living with AIDS in Africa: The role of primary health-care workers. Australian Journal of Rural Health 9: 158-165.

13. Ahmed MU, Seriwala HM, Danish SH, Khan AM, Hussain $\mathrm{M}$, et al. (2016) Knowledge, attitude, and self care practices amongsts patients with type 2 diabetes in Pakistan. Glob J Health Sci 8: 1-8.

14. Boels AM, Vos RC, Metzendorf MI, Rutten GEHM (2017) Diabetes self-management education and support delivered by mobile health ( $m$-health) interventions for adults with type 2 diabetes mellitus. Cochrane Reviews.

15. Afemikhe JA, Jooste K, Chipps JA (2016) Knowledge and practice of self- management among patients with type 2 diabetes in Benin City, Nigeria.

16. Inzucchi SE (2011) Diabetic facts and guidelines.

17. Jackson I L, Adibe MO, Okonta MJ, Ukwe CV (2014) Knowledge of self-care among type 2 diabetes patients in two states of Nigeria. Pharm Pract (Granada) 12: 404.

18. Heisler M, Pietee JD, Spencer M, Kieffer E, Vijan S (2005) The relationship between knowledge of recent $\mathrm{HbA} 1 \mathrm{c}$ values and diabetes care understanding and self-management. Diabetes Care 28: 816-822.

19. Gulabani M, John M, Isaac R (2008) Knowledge of diabetes, its treatment and complications amongst diabetic patients in a tertiary care hospital. Indian J Med 33: 204-206.

20. Mukeshimana1 M, Hakizimana G, Mwali C, Umuhoza C Uwambajimana J, et al. (2015) The knowledge and practice of self-care management among patients attending a diabetes clinic in Kigali, Rwanda. Rwanda Journal 2: 24-30.

21. Baradaran HR, Shams-Hosseini N, Noori-Hekmat S, Tehrani-Banihashemi A, Khameseh ME (2010) Effectiveness of diabetes educational interventions in Iran: A systematic review. Diabetes Technol Ther 12: 317-331.

22. Beverly EA, Worley MF, Court AB, Kayla EP, Ivanoy NN (2016) Patient-physician communication and diabetes self-care. Journal of Clinical Outcomes Management 23.

23. Mabaso RG, Oduntan OA (2016) Knowledge and practices related to diabetes mellitus among adults with diabetes in the Mopani District, Limpopo Province, South Africa. African Vision Eye Health 75: 324.

24. Iregbu SC, Iregbu F U (2016) A review of self-management of diabetes in Africa. African Journal of Diabetes Medicine 24
25. Glezeva M, Chisale M, McDonald K, Ledwidge M, Gallagher J, et al. (2018) Diabetes and complications of the heart in Sub-Saharan Africa: An urgent need for improved awareness, diagnostics and management. Diabetes Res Clin Pract 137: 10-19.

26. Aklilu T, Hiko D, Mohammed MA (2014) Diabetic patients' Knowledge of Their Disease, Therapeutic Goals, and Self-management: Association with goal attainment at Dessie referral hospital, Ethiopia. Ther Innov Regul Sci 48: 583-591.

27. Rajasekharan D, Kulkarni V, Unnikrishnan B, Kumar N, Holla R, et al. (2015) Self-care activities among patients with diabetes attending a tertiary care hospital in Mangalore Karnataka, India. Ann Med Health Sci Res 5: 59-64.

28. White H, Sabarwal S (2014) Quasi experimental design and methods, Methodological briefs: Impact evaluation 8, UNICEF office of Research, Florence.

29. Axelrod, Hayward (2006) Nonrandomized interventional study designs (Quasi- Experimental Designs). In: Penson DF, Wei JT, Clinical Research Methods for Surgeons. Totowa, New Jersey, 63-76.

30. Schmitt A, Gahr A, Hermanns N, Kulzer B, Huber J, et al. (2013) The diabetes self-management questionnaire (DSMQ): Development and evaluation of an instrument to assess diabetes self-care activities associated with glycaemic control. Health and Quality of Life Outcomes 11: 138.

31. Ministry of Public Health and Sanitaition (2010) Self-management module. Kenya National Diabetes Educators Manual, 52-85.

32. Kushwaha AS, Kumari S, Kushwaha N (2016) Self-care in diabetes: A study amongst diabetics in an urban community. International Journal of Community Medicine and Public Health 3: 293-298.

33. Shane-McWhorter L, McAdam-Marx C, Lenert L, Petersen M, Woolsey S, et al. (2015) Pharmacist-provided diabetes management and education via a telemonitoring program. J Am Pharm Assoc 55: 516-526.

34. Chylińska J, Łazarewicz M, Rzadkiewicz M, Adamus M, Jaworski M, et al. (2017) The role of gender in the active attitude toward treatment and health among older patients in primary health care-self-assessed health status and socio-demographic factors as moderators. BMC Geriatr 17: 284.

35. Bosu WK (2015) An overview of the nutrition transition in West Africa: Implications for non-communicable diseases. Proc Nutr Soc 74: 466-477.

36. World Health Organization (2016) Global report on diabetes. Geneva, Switzerland.

37. Amugsi DA, Dimbuene ZT, Mberu B, Muthuri S, Ezeh AC (2017) Prevalence and time trends in overweight and obesity among urban women: An analysis of demographic and health surveys data from 24 African Countries, 1991-2014. BMJ Open 7: e017344.

38. Mobula LM, Sarfo FS, Carson KA, Burnham G, Arthur L, et al. (2018) Predictors of glycemic control in type-2 diabetes mellitus: Evidence from a multicenter study in Ghana. Translational Metabolic Syndrome Research 1: 1-8.

39. Awodele O, Osuolale JA (2015) Medication adherence in type 2 diabetes patients: Study of patients in Alimosho General Hospital, Igando, Lagos, Nigeria. Afr Health Sci 15: 513-522.

40. Al-Maskari F, El-Sadig M, Al-Kaabi JM, Afandi B, Nagelker- 
ke N, et al. (2013) Knowledge, attitude and practices of diabetic patients in the United Arab Emirates. PLoS One 8: e52857.

41. Albargawi M, Snethen J, Al Gannass A, Kelber S (2017) Relationship between person's health beliefs and diabetes self-care management regimen. J Vasc Nurs 35: 187-192.

42. Fadare J, Olamoyegun M, Gbadegesin BA (2015) Medication adherence and direct treatment cost among diabetes patients attending a tertiary healthcare facility in Ogbomosho, Nigeria. Malawi Med J 27: 65-70.

43. Olorunfemi O, Ojewole F (2018) Medication belief as correlate of medication adherence among patients with diabetes in Edo State, Nigeria. Nursing Open 6: 197-202.

44. (2019) National Bureau of Statistics.

45. Adibe MO, Aguwa CN, Ukwe CV (2011) The construct validity of an instrument for measuring type 2 diabetes self-ca- re knowledge in Nigeria. Tropical Journal of Pharmaceutical Research 10.

46. Niguse H, Belay G, Fisseha G, Desale T, Gebremedhn G (2019) Self-care related knowledge, attitude, practice and associated factors among patients with diabetes in Ayder Comprehensive Specialized Hospital, North Ethiopia. BMC Res Notes 12: 34.

47. Addisu Y, Eshete A, Hailu E (2013) Assessment of diabetic patient perception on diabetic disease and self-care practice in Dilla University Referral Hospital, South Ethiopia. Journal of Metabolic Syndrome 3: 166.

48. Abbasi YF, See OG, Ping NY, Balasubramanian GP, Cheng $\mathrm{H}$, et al. (2018) Diabetes knowledge, attitude and practice among type 2 diabetes mellitus patients in Kuala Muda District, Malysia- A cross-sectional study. Diabetes Metab Syndr 12: 1057-1063. 